\title{
Factors Associated With the Experience of Cognitive Training Apps for the Prevention of Dementia: Cross-sectional Study Using an Extended Health Belief Model
}

Jaegyeong Lee ${ }^{1}$, RN, MSN, PhD; Jung Min $\mathrm{Lim}^{2}$, MD

${ }^{1}$ College of Nursing, Seoul National University, Seoul, Republic of Korea

${ }^{2}$ Department of Pharmacology, Yonsei University College of Medicine, Seoul, Republic of Korea

Corresponding Author:

Jung Min Lim, MD

Department of Pharmacology

Yonsei University College of Medicine

Avison Biomedical Research Center, Room 318

50-1 Yonsei-ro, Seodaemun-gu

Seoul, 03722

Republic of Korea

Phone: 82222280925

Email: dreamist88@gmail.com

\section{Abstract}

Background: The prevalence and economic burden of dementia are increasing dramatically. Using information communication technology to improve cognitive functions is proven to be effective and holds the potential to serve as a new and efficient method for the prevention of dementia.

Objective: The aim of this study was to identify factors associated with the experience of mobile apps for cognitive training in middle-aged adults. We evaluated the relationships between the experience of cognitive training apps and structural variables using an extended health belief model.

Methods: An online survey was conducted on South Korean participants aged 40 to 64 years (N=320). General characteristics and dementia knowledge were measured along with the health belief model constructs. Statistical analysis and logistic regression analysis were performed.

Results: Higher dementia knowledge (odds ratio [OR] 1.164, $P=.02$ ), higher perceived benefit $(\mathrm{OR} 1.373, P<.001)$, female gender (OR $0.499, P=.04$ ), and family history of dementia (OR 1.933, $P=.04$ ) were significantly associated with the experience of cognitive training apps for the prevention of dementia.

Conclusions: This study may serve as a theoretical basis for the development of intervention strategies to increase the use of cognitive training apps for the prevention of dementia.

(J Med Internet Res 2022;24(1):e31664) doi: 10.2196/31664

\section{KEYWORDS}

cognitive training apps; dementia knowledge; health belief model; middle-aged; logistic regression analysis; dementia; Alzheimer disease; cognition; mobile apps; health apps

\section{Introduction}

\section{Background}

Population aging is a worldwide phenomenon, and the proportion of the elderly is increasing dramatically in developed countries. Along with this trend, the prevalence of dementia, which mainly affects older people, is also growing substantially. Currently, 6.2 million (11.3\%) Americans aged 65 years or older have Alzheimer disease (AD), which is expected to grow more than twice by 2050 [1]. Similarly, 0.75 million (10.2\%) South Koreans aged 65 or older are living with dementia, which is estimated to reach 3 million $(16.1 \%)$ by 2050 [2]. The cost of health care for dementia patients is also becoming a huge burden, annually spending US \$355 billion in the United States [1] and US \$1 billion in South Korea [2]. 
Although AD commonly affects the elderly, the first patient reported was a middle-aged person [3]. Early-onset AD, which refers to a diagnosis of AD before the age of 65 years, accounts for about 5\% of all AD [4]. The main symptoms may seem similar, although the diagnosis is greatly delayed and shows a more aggressive course of disease [5]. General management strategies for early-onset $\mathrm{AD}$ are similar to senile $\mathrm{AD}$, but targeted cognitive therapies and age-appropriate psychosocial support are critical [5]. Awareness of the disease entity is relatively low, and most studies on $\mathrm{AD}$ are focused on adults over 65 years of age, leaving out the early onset population. The middle-aged are a unique age group. There are many middle-aged people who, on the one hand, experience with parents or relatives suffering from dementia; on the other hand, many of them are susceptible to early-onset AD. Therefore, this group deserves more attention.

Numerous preventive measures may help manage the growing burden of AD. Meta-analysis suggested that if some modifiable risk factors for $\mathrm{AD}$ were reduced by $10-20 \%$ per decade, the prevalence of dementia in 2050 could be decreased by $8-15 \%$ [6]. Moreover, engaging in mentally stimulating activities can greatly decrease the risk of developing $\mathrm{AD}$ [7], and low education attainment is known as the largest modifiable risk factor for AD development [8]. Therefore, early intervention of risk factors and active prevention measures may greatly decrease the socioeconomic burden of dementia.

Behavioral changes leading to the prevention of dementia are greatly influenced by personal beliefs that dementia can be prevented or by personal experiences with patients with dementia [9]. These perceptions about dementia can also be negatively affected by inaccurate knowledge about dementia. If someone's level of awareness for the causes and symptoms of dementia is low, they are less likely to participate in preventive activities for dementia, which may lead to delayed diagnosis and treatment [10,11]. Therefore, knowledge and perceptions about dementia is very important for the proper management of the disease [12]. However, according to a systematic review on the knowledge about dementia in the general population, 19 out of 40 reports showed that the level of dementia knowledge was low or very limited [13]. Another study found that the middle-aged population showed low levels of knowledge regarding dementia risk factors $[14,15]$. Therefore, the middle-aged may perceive dementia as a nonpreventable disease and may be less likely to take preventive measures.

Today, various mobile apps are being developed and utilized for the early detection or prevention of health conditions. Apps developed for dementia prevention mainly focus on cognitive training or stimulation, which may improve cognitive functions such as memory, concentration, or visuospatial coordination [16-20]. Many studies have shown that using these apps can improve memory and enhance quality of life, both in healthy adults and individuals with mild cognitive impairment [20-24].

Despite the reported usefulness of this technology, factors associated with the use of cognitive training apps for dementia prevention have not been reported in the literature. The use of cognitive training apps for dementia prevention is a combination of health-related behavior and the acceptance of technology.
The health belief model (HBM) is widely used to predict the determinants related to health-related behaviors, which evaluates constructs including perceived benefits, perceived barriers, perceived susceptibility, and perceived severity to understand the likelihood of behavior [25]. The technology acceptance model is used to evaluate the causes that affect people to accept or reject technology, which measures perceived ease of use and perceived usefulness to explain usage intentions and behavior $[26,27]$. As each model has its limitations to explain the use of health-related apps, many recent studies have attempted to extend or combine models for better explanations of the factors that affect the acceptance of mobile health care apps [28-31].

\section{Objective}

The aim of this study was to investigate the association of structural variables and perceived health belief constructs with the experience of cognitive training apps in middle-aged adults, based on the HBM. Perceived benefits and barriers were measured for the use of cognitive training apps, and perceived susceptibility and severity was measured for dementia. Additionally, we included dementia knowledge as an additional variable to increase the explanatory power of our model.

\section{Methods}

\section{Recruitment}

Data were collected from middle-aged adults in South Korea aged 40 to 64 years between February 4 and February 8, 2021. The participants were recruited online by a professional agency (Macromill Embrain Co), where about 1.3 million participants from the general population are maintained by a demographic distribution based on census data from the National Statistical Office. First, a weblink or notice was sent to the participants via email or mobile app, whereby all participants were informed about the purpose of the study via online documentation on the starting page. The information was available for download if needed. The participants voluntarily moved onto the survey by clicking the start button, which was considered as an informed consent. Next, the participants were asked to respond to an online questionnaire. The full survey is provided in Multimedia Appendices 1 and 2. One of the unique features of an online survey is that the survey does not progress to the next question if an answer is omitted or inaccurate, which prevents incomplete or inaccurate data. The participants were free to drop out at any point of the survey if they wanted to. All personal identifying information was removed from the collected data. This study was approved by the institutional review board of Seoul National University (2102/002-002).

A total of 547 participants initially accessed the survey; 2 people did not satisfy the age criteria, and 39 dropped out before completion. Of the remaining 506 participants, 362 were selected using the proportionate quota sampling method for age and gender, due to oversampling. Participants in their 40s, 50s, and 60s were included at a 2:2:1 ratio, and men and women were selected at a 1:1 ratio, respectively. Of the selected 362 people, 42 were excluded due to poor data quality, which included extremely short response times or giving same answers for all items. In conclusion, 320 participants were included in the final analysis. 


\section{Measures}

The participants rated each of the following items on a 5-point Likert scale $(1=$ strongly disagree to $5=$ strongly agree), unless stated otherwise.

\section{General Characteristics}

Age, gender, education level, marital status, chronic diseases, family history of dementia, and experience of using cognitive training apps were assessed with standard survey items.

\section{Dementia Knowledge}

Dementia knowledge was measured with a dementia awareness scale developed for a national survey on the prevalence of dementia in South Korea [2], which evaluates the individual's knowledge about various aspects of dementia. The scale consists of 15 items which are answered "yes," "no," or "don't know" (to account for false positives), and the number of correct answers is summed up to a final score.

\section{Perceived Benefit and Barrier of Using Cognitive Training Apps}

The perceived benefit of using apps for cognitive training was measured with 4 items adapted from Venkatesh and Davis [27]. The questions were originally used to measure the perceived usefulness of accepting technology, which were modified for using apps and adapted in Korean for this study. The perceived barrier of using apps for cognitive training was measured with a modified set of 5 items described previously [32]. The items were originally used to measure the perceived barriers of using mobile health apps, which were modified for cognitive training apps in this study.

\section{Perceived Susceptibility and Severity of Dementia}

The perceived susceptibility of dementia and severity of dementia was measured with 4 items each, derived from the intention-to-screen questionnaire originally described by Galvin et al [33] and adapted in Korean by Yoo and Kim [34].

\section{Statistical Analysis}

Data were analyzed with SPSS, version 22.0 (IBM Corp). The differences between the groups were analyzed using the Student $t$ test or one-way analysis of variance (ANOVA), and $P<.05$ was considered statistically significant. We performed logistic regression analysis to examine the relationships between the measured variables and the experience of cognitive training apps.

\section{Results}

\section{General Characteristics}

The general characteristics of the study sample are shown in Table 1 . Of the 320 respondents, 82 (25.6\%) had experience with cognitive training apps, while $238(74.4 \%)$ did not. We compared the general characteristics between these 2 groups. Within the study sample, $62.2 \%(\mathrm{n}=51)$ of participants from the experienced group were female, compared to $47.1 \%(\mathrm{n}=112)$ for the nonexperienced group $\left(X^{2}=5.591, P=.02\right)$. Participants with a family history of dementia accounted for $29.3 \%(n=24)$ in the experienced group, which was significantly higher compared with $16.8 \%(\mathrm{n}=40)$ for the nonexperienced group $\left(X^{2}=5.919, P=.02\right)$. 
Table 1. Comparison of general characteristics according to experience of cognitive training apps $(\mathrm{N}=320)$.

\begin{tabular}{|c|c|c|c|c|c|}
\hline \multirow[t]{2}{*}{ Variables } & \multirow{2}{*}{$\begin{array}{l}\text { All participants } \\
(\mathrm{N}=320)\end{array}$} & \multicolumn{4}{|c|}{ Experience of cognitive training apps } \\
\hline & & Yes $(n=82)$ & No $(\mathrm{n}=238)$ & $x^{2}$ & $P$ value \\
\hline Age range (years), n (\%) & & & & 2.850 & .24 \\
\hline $40-49$ & $124(38.8)$ & $26(31.7)$ & $98(41.2)$ & & \\
\hline $50-59$ & $129(40.3)$ & $39(47.6)$ & $90(37.8)$ & & \\
\hline $60-64$ & $67(20.9)$ & $17(20.7)$ & $50(21.0)$ & & \\
\hline Gender, $\mathbf{n}(\%)$ & & & & 5.591 & .02 \\
\hline Male & $157(49.1)$ & $31(37.8)$ & $126(52.9)$ & & \\
\hline Female & $163(50.9)$ & $51(62.2)$ & $112(47.1)$ & & \\
\hline Education level, n (\%) & & & & 2.506 & .29 \\
\hline High school & $74(23.1)$ & $23(28.0)$ & $51(21.4)$ & & \\
\hline College & $211(65.9)$ & $53(64.6)$ & $158(66.4)$ & & \\
\hline Graduate school & $35(10.9)$ & $6(7.3)$ & $29(12.2)$ & & \\
\hline Marital status, n (\%) & & & & 0.366 & .83 \\
\hline Single & $40(12.5)$ & $9(11.0)$ & $31(13.0)$ & & \\
\hline Married & $256(80.0)$ & $65(80.5)$ & $190(79.8)$ & & \\
\hline Other & $24(7.5)$ & $7(8.5)$ & $17(7.1)$ & & \\
\hline Chronic diseases, n (\%) & & & & 0.381 & .54 \\
\hline Yes & $112(35.0)$ & $31(37.8)$ & $81(34.0)$ & & \\
\hline No & $208(65.0)$ & $51(62.2)$ & $157(66.0)$ & & \\
\hline Family history of dementia, n (\%) & & & & 5.919 & .02 \\
\hline Yes & $64(20.0)$ & $24(29.3)$ & $40(16.8)$ & & \\
\hline No or other & $256(80.0)$ & $58(70.7)$ & $198(83.2)$ & & \\
\hline
\end{tabular}

\section{Descriptive Statistics of Study Variables}

Descriptive statistics of the measured study variables according to experience of cognitive training apps are shown in Table 2. The participants with experience of cognitive training apps showed higher levels of dementia knowledge $(P<.001)$ and perceived benefit of using cognitive training apps $(P<.001)$, compared with nonexperienced individuals. The perceived barrier of using cognitive training apps was lower $(P=.02)$ in the experienced group. Both perceived susceptibility and severity of dementia did not show significant differences between the groups.

Table 2. Comparison of measured variables according to experience of cognitive training apps $(\mathrm{N}=320)$.

\begin{tabular}{|c|c|c|c|c|c|}
\hline \multirow[t]{2}{*}{ Variables } & \multirow{2}{*}{$\begin{array}{l}\text { All participants } \\
(\mathrm{N}=320)\end{array}$} & \multicolumn{2}{|c|}{ Experience of cognitive training apps } & \multirow[b]{2}{*}{$t$ value } & \multirow[b]{2}{*}{$P$ value } \\
\hline & & Yes $(n=82)$ & No $(n=238)$ & & \\
\hline Dementia knowledge, mean (SD) & $9.05(2.28)$ & $9.87(2.42)$ & $8.77(2.17)$ & 3.817 & $<.001$ \\
\hline Perceived benefit of using apps, mean (SD) & $14.92(2.47)$ & $16.16(2.12)$ & $14.50(2.45)$ & 5.875 & $<.001$ \\
\hline Perceived barrier of using apps, mean (SD) & $13.44(3.08)$ & $12.76(3.27)$ & $13.68(2.98)$ & -2.354 & .02 \\
\hline Perceived susceptibility of dementia, mean (SD) & $11.45(2.83)$ & $11.04(3.05)$ & $11.59(2.75)$ & -1.524 & .13 \\
\hline Perceived severity of dementia, mean (SD) & $14.51(2.40)$ & $14.62(2.54)$ & $14.47(2.35)$ & .506 & .61 \\
\hline
\end{tabular}

\section{Factors Associated With the Experience of Cognitive Training Apps}

Based on the statistical analyses above, we included 2 general characteristics (gender and family history of dementia) and 3 measured variables (dementia knowledge, perceived benefit, and perceived barrier) as possible predicting factors of the experience of cognitive training apps for logistic regression analysis (Table 3 ). The results revealed that higher dementia knowledge (odds ratio [OR] 1.164, $P=.02$ ), higher perceived benefit (OR 1.373, $P<.001$ ), female gender (OR 0.548, $P=.04$ ), and family history of dementia (OR 1.933, $P=.04)$ showed positive relationships with experience of cognitive training apps for the prevention of dementia. 
Table 3. Predicting factors of experience of cognitive training apps.

\begin{tabular}{|c|c|c|c|c|c|}
\hline Variables & $\mathrm{B}^{\mathrm{a}}$ & SE & $\mathrm{OR}^{\mathrm{b}}$ & $95 \% \mathrm{CI}$ & $P$ value \\
\hline Dementia knowledge & 0.152 & 0.067 & 1.164 & $1.021-1.328$ & .02 \\
\hline Perceived benefit of using apps & 0.317 & 0.072 & 1.373 & $1.192-1.581$ & $<.001$ \\
\hline Perceived barrier of using apps & -0.033 & 0.047 & 0.499 & $0.480-0.967$ & .48 \\
\hline Gender $($ male $=1)$ & -0.601 & 0.285 & .548 & $0.314-0.958$ & .04 \\
\hline Family history of dementia (yes $=1$ ) & 0.659 & 0.327 & 1.933 & $1.018-3.669$ & .04 \\
\hline Constant & -8.314 & 1.882 & 0.000 & $ـ^{c}$ & - \\
\hline
\end{tabular}

${ }^{\mathrm{a}} \mathrm{B}$ : unstandardized regression weight.

${ }^{\mathrm{b}} \mathrm{OR}$ : odds ratio.

${ }^{\mathrm{c}}$ Not applicable.

\section{Discussion}

\section{Principal Findings}

This study investigated the factors associated with the actual use of cognitive training apps for the prevention of dementia in middle-aged adults. Among the 320 participants, only 82 (25.6\%) reported to have experience with cognitive training apps, which is still quite low, considering the widespread distribution and frequent usage of smartphones and related apps in South Korea. As the amount of evidence on the efficacy of cognitive training apps for improving cognitive functions or preventing dementia is increasing [21-23], facilitating the use of mobile apps for dementia care could be an easy solution with multiple positive effects. Conventional offline dementia prevention programs require physical space and human resources, and physical disabilities of an individual may limit access to the program [35]. Innovative programs that utilize mobile apps can overcome these hurdles, which may also lead to continued use. In addition, gamified cognitive training apps are fun and motivational, cost very little, and can be performed in a comfortable environment at a convenient time [36], which could greatly increase adherence. However, one must note that not all cognitive training apps are based on scientific evidence, and therefore these ideas should not be generalized. Further studies investigating the effects of specific cognitive training apps and the types of cognitive training included are needed, which would shed light on how to select a cognitive training app for the prevention of dementia.

Our results showed that the perceived benefit of using cognitive training apps was positively associated with the use of cognitive training apps, but other HBM constructs did not. Previous studies also suggest that perceived benefit is a consistent predictor of health-related behavior, while perceived susceptibility and severity often failed to explain health-related behavior [37-39]. Additionally, previous studies using the technology acceptance model also showed that the perceived usefulness of using apps is a positive predictor of the intention to use the apps [40-42]. In other words, believing that using cognitive training apps can improve cognitive function is an important factor in predicting the intention to use the apps. Moreover, this belief is also critical for the continued use of health apps $[43,44]$.

Dementia knowledge was linked to the actual use of cognitive training apps in this study, which is consistent with previous reports showing that dementia knowledge is positively associated with preventive behavior for dementia [45-47]. A systematic review on dementia knowledge points out that most people think cognitive activities that exercise the brain are more effective in preventing dementia rather than medications, exercise, or dietary modifications [48], which may explain the link between dementia knowledge and the use of cognitive training apps.

Meanwhile, the average dementia knowledge score in this study was 9.05 points out of 15 . Recent studies on middle-aged adults (40 to 75 years of age) showed that more than half of the respondents had insufficient dementia knowledge, $59.4 \%$ wanted information for cognitive health, and $70 \%$ had positive feelings for eHealth use to improve cognitive health $[14,15]$. As both the need and demand for dementia-related education is high, mobile apps can serve as a useful tool to deliver dementia knowledge and provide cognitive training programs in the middle-aged compared to the elderly, in terms of technology friendliness.

Our results showed that women were more likely to use cognitive training apps than men. This is consistent with a previous study, which showed women participate in activities that help improve cognitive health more frequently than men [49]. This may be linked to the higher prevalence of dementia among women compared with men [50], and the higher level of experience with dementia patients in females [1], although further studies are required to elucidate the exact relationships between these factors.

Finally, individuals with a family history of dementia were more likely to use cognitive training apps in this study. Previous studies show that people with a family history of dementia think that they have a higher risk of developing dementia, and as having a family history of AD has consistently emerged as a key predictor of dementia worry [51], they may undergo activities for dementia prevention more actively. However, our results showed that perceived susceptibility did not predict the use of cognitive training apps, similar to the findings of a previous report that showed self-perceived risk itself did not predict preventive behavior [52]. Other studies also show that people with family history of dementia are less likely to believe 
that dementia is preventable, and that they have lower self-efficacy for dementia prevention [53]. Therefore, it is important to understand the characteristics of this population and perform suitable interventions, which can lead to a positive attitude for dementia prevention.

\section{Limitations}

The questionnaire data was collected on an online basis; therefore, individuals could have shown higher digital literacy compared with the normal population.

\section{Conclusions}

This study explores the influencing factors on the experience of cognitive training apps using an extended HBM model, which may serve as a theoretical basis for the development of intervention strategies to increase the use of cognitive training apps for dementia prevention.

\section{Authors' Contributions}

JL and JML conceived and designed the study, analyzed data, and wrote the manuscript.

\section{Conflicts of Interest}

None declared.

\section{Multimedia Appendix 1}

Full questionnaire (in Korean).

[DOCX File, 766 KB-Multimedia Appendix 1]

\section{Multimedia Appendix 2}

Full questionnaire (in English).

[DOCX File, 765 KB-Multimedia Appendix 2]

\section{References}

1. Alzheimer's Association. 2021 Alzheimer's disease facts and figures. Alzheimers Dement 2021 Mar;17(3):327-406. [doi: 10.1002/alz.12328] [Medline: 33756057]

2. Korean Dementia Observatory 2019. National Institute of Dementia.: National Institute of Dementia; 2020 Feb 28. URL: https://www.nid.or.kr/info/dataroom view.aspx?bid=209 [accessed 2021-08-24]

3. Maurer K, Volk S, Gerbaldo H. Auguste D and Alzheimer's disease. Lancet 1997 May 24;349(9064):1546-1549. [doi: 10.1016/S0140-6736(96)10203-8] [Medline: 9167474]

4. Zhu X, Tan L, Wang H, Jiang T, Cao L, Wang C, et al. Rate of early onset Alzheimer's disease: a systematic review and meta-analysis. Ann Transl Med 2015 Mar;3(3):38. [doi: 10.3978/j.issn.2305-5839.2015.01.19] [Medline: 25815299]

5. Mendez MF. Early-Onset Alzheimer Disease. Neurol Clin 2017 May;35(2):263-281 [FREE Full text] [doi: 10.1016/j.ncl.2017.01.005] [Medline: 28410659]

6. Norton S, Matthews FE, Barnes DE, Yaffe K, Brayne C. Potential for primary prevention of Alzheimer's disease: an analysis of population-based data. Lancet Neurol 2014 Aug;13(8):788-794. [doi: 10.1016/S1474-4422(14)70136-X] [Medline: 25030513]

7. Crous-Bou M, Minguillón C, Gramunt N, Molinuevo JL. Alzheimer's disease prevention: from risk factors to early intervention. Alzheimers Res Ther 2017 Sep 12;9(1):71 [FREE Full text] [doi: 10.1186/s13195-017-0297-z] [Medline: $\underline{28899416]}$

8. Barnes DE, Yaffe K. The projected effect of risk factor reduction on Alzheimer's disease prevalence. Lancet Neurol 2011 Sep;10(9):819-828 [FREE Full text] [doi: 10.1016/S1474-4422(11)70072-2] [Medline: 21775213]

9. Low L, Anstey KJ. The public's perception of the plausibility of dementia risk factors is not influenced by scientific evidence. Dement Geriatr Cogn Disord 2007;23(3):202-206. [doi: 10.1159/000099038] [Medline: 17259711]

10. Akyol MA, Zehirlioğlu L, Erünal M, Mert H, Hatipoğlu NS, Küçükgüçlü Ö. Determining Middle-Aged and Older Adults' Health Beliefs to Change Lifestyle and Health Behavior for Dementia Risk Reduction. Am J Alzheimers Dis Other Demen 2020 Jan;35:1533317519898996 [FREE Full text] [doi: 10.1177/1533317519898996] [Medline: $\underline{32048860]}$

11. Leung AYM, Molassiotis A, Zhang J, Deng R, Liu M, Van IK, et al. Dementia Literacy in the Greater Bay Area, China: Identifying the At-Risk Population and the Preferred Types of Mass Media for Receiving Dementia Information. Int J Environ Res Public Health 2020 Apr 07;17(7):2511 [FREE Full text] [doi: 10.3390/ijerph17072511] [Medline: 32272551 ]

12. Nationwide Survey on the Dementia Epidemiology of Korea. National Institute of Dementia. 2017 Jun 30. URL: https:/ /www.nid.or.kr/info/dataroom view.aspx?bid=182 [accessed 2021-06-10]

13. Cahill S, Pierce M, Werner P, Darley A, Bobersky A. A systematic review of the public's knowledge and understanding of Alzheimer's disease and dementia. Alzheimer Dis Assoc Disord 2015;29(3):255-275. [doi: 10.1097/WAD.0000000000000102] [Medline: 26207322] 
14. Van Asbroeck S, van Boxtel MPJ, Steyaert J, Köhler S, Heger I, de Vugt M, et al. Increasing knowledge on dementia risk reduction in the general population: Results of a public awareness campaign. Prev Med 2021 Jun;147:106522 [FREE Full text] [doi: 10.1016/j.ypmed.2021.106522] [Medline: 33744328]

15. Heger I, Köhler S, van Boxtel M, de Vugt M, Hajema K, Verhey F, et al. Raising awareness for dementia risk reduction through a public health campaign: a pre-post study. BMJ Open 2020 Nov 06;10(11):e041211 [FREE Full text] [doi: 10.1136/bmjopen-2020-041211] [Medline: 33158836]

16. Hill NL, Mogle J, Wion R, Kitt-Lewis E, Hannan J, Dick R, et al. App-based attention training: Incorporating older adults' feedback to facilitate home-based use. Int J Older People Nurs 2018 Mar;13(1):e12163. [doi: 10.1111/opn.12163] [Medline: 28752612]

17. Lu M, Lin W, Yueh H. Development and Evaluation of a Cognitive Training Game for Older People: A Design-based Approach. Front Psychol 2017 Oct 17;8:1837. [doi: 10.3389/fpsyg.2017.01837] [Medline: 29089914]

18. Powell LE, Wild MR, Glang A, Ibarra S, Gau JM, Perez A, et al. The development and evaluation of a web-based programme to support problem-solving skills following brain injury. Disabil Rehabil Assist Technol 2019 Jan;14(1):21-32. [doi: 10.1080/17483107.2017.1389999] [Medline: 29063800]

19. Tacchino A, Pedullà L, Bonzano L, Vassallo C, Battaglia MA, Mancardi G, et al. A New App for At-Home Cognitive Training: Description and Pilot Testing on Patients with Multiple Sclerosis. JMIR Mhealth Uhealth 2015 Aug 31;3(3):e85 [FREE Full text] [doi: 10.2196/mhealth.4269] [Medline: 26323749]

20. Oh SJ, Seo S, Lee JH, Song MJ, Shin M. Effects of smartphone-based memory training for older adults with subjective memory complaints: a randomized controlled trial. Aging Ment Health 2018 Apr;22(4):526-534. [doi: 10.1080/13607863.2016.1274373] [Medline: 28071929]

21. Yasini M, Marchand G. Adoption and Use of a Mobile Health Application in Older Adults for Cognitive Stimulation. Stud Health Technol Inform 2016;221:13-17. [doi: 10.3233/978-1-61499-633-0-13] [Medline: 27071867]

22. Shellington EM, Felfeli T, Shigematsu R, Gill DP, Petrella RJ. HealthBrain: an innovative smartphone application to improve cognitive function in older adults. Mhealth 2017 May;3(5):17 [FREE Full text] [doi: 10.21037/mhealth.2017.04.05] [Medline: 28567413]

23. Han JW, Son KL, Byun HJ, Ko JW, Kim K, Hong JW, et al. Efficacy of the Ubiquitous Spaced Retrieval-based Memory Advancement and Rehabilitation Training (USMART) program among patients with mild cognitive impairment: a randomized controlled crossover trial. Alzheimers Res Ther 2017 Jun 06;9(1):39 [FREE Full text] [doi: 10.1186/s13195-017-0264-8] [Medline: 28587629]

24. Martínez-Alcalá CI, Rosales-Lagarde A, Hernández-Alonso E, Melchor-Agustin R, Rodriguez-Torres EE, Itzá-Ortiz BA. A Mobile App (iBeni) With a Neuropsychological Basis for Cognitive Stimulation for Elderly Adults: Pilot and Validation Study. JMIR Res Protoc 2018 Aug 21;7(8):e172 [FREE Full text] [doi: 10.2196/resprot.9603] [Medline: 30131319]

25. Rosenstock IM. Historical Origins of the Health Belief Model. Health Education Monographs 1974 Dec 01;2(4):328-335. [doi: 10.1177/109019817400200403]

26. Davis FD. Perceived Usefulness, Perceived Ease of Use, and User Acceptance of Information Technology. MIS Quarterly 1989 Sep;13(3):319-340. [doi: 10.2307/249008]

27. Venkatesh V, Davis FD. A Theoretical Extension of the Technology Acceptance Model: Four Longitudinal Field Studies. Management Science 2000 Feb;46(2):186-204. [doi: 10.1287/mnsc.46.2.186.11926]

28. Ahadzadeh AS, Pahlevan Sharif S, Ong FS, Khong KW. Integrating health belief model and technology acceptance model: an investigation of health-related internet use. J Med Internet Res 2015 Feb 19;17(2):e45 [FREE Full text] [doi: 10.2196/jmir.3564] [Medline: 25700481]

29. Bae H, Jo SH, Lee E. Influence of Locus of Control and Belief in Health Promotion Behavior on the Intention to Use Mobile Healthcare Services. Journal of Marketing Management Research 2019 Apr;24(2):55-71. [doi: 10.37202/KMMR.2019.24.2.55]

30. Moon J, Rigg JS, Smith JE. Korean American Smokers' Perspectives on Mobile Smoking Cessation Applications. Tob Use Insights 2020 Dec 13;13:1179173X20972384 [FREE Full text] [doi: 10.1177/1179173X20972384] [Medline: 33402856$]$

31. Hong W, Liu R, Ding Y, Hwang J, Wang J, Yang Y. Cross-Country Differences in Stay-at-Home Behaviors during Peaks in the COVID-19 Pandemic in China and the United States: The Roles of Health Beliefs and Behavioral Intention. Int J Environ Res Public Health 2021 Feb 21;18(4):2104 [FREE Full text] [doi: 10.3390/ijerph18042104] [Medline: 33670078]

32. Wang JS. A Study on Factors Influencing the Individual's Health Beliefs on the Intention of Mobile Health Care Applications: Focusing on the e-health literacy control effects (MA Thesis). Research Information Sharing Service.: Kyung Hee University; 2020. URL: https://tinyurl.com/2s35bc48 [accessed 2021-06-30]

33. Galvin JE, Scharff DP, Glasheen C, Fu Q. Development of a population-based questionnaire to explore psychosocial determinants of screening for memory loss and Alzheimer Disease. Alzheimer Dis Assoc Disord 2006;20(3):182-191. [doi: 10.1097/00002093-200607000-00010] [Medline: 16917189]

34. Yoo R, Kim GS. Factors Affecting the Performance of the Dementia Screening Test Using the Health Belief Model. Journal of Korean Public Health Nursing 2017 Dec;31(3):464-477 Print ISSN: 1226-0290 / Online ISSN: 2234-2869. [doi: 10.5932/JKPHN.2017.31.3.464] 
35. Kim SJ, Choi YJ. Predictable Effect and Usability of Smart-Phone Application for Elderly Dementia Prevention. Journal of Industrial Convergence 2019 Dec 31;17(4):87-94. [doi: 10.22678/jic.2019.17.4.087]

36. Giannopoulou P, Vlamos P. Analysis and design of an information system for cognitive training of patients with mild cognitive impairment using mobile devices. 2020 Sep Presented at: 2020 5th South-East Europe Design Automation, Computer Engineering, Computer Networks and Social Media Conference (SEEDA-CECNSM); 2020 Sep 25-27; Virtual Event. [doi: 10.1109/seeda-cecnsm49515.2020.9221782]

37. Floyd DL, Prentice-Dunn S, Rogers RW. A Meta-Analysis of Research on Protection Motivation Theory. J Appl Social Pyschol 2000 Feb;30(2):407-429. [doi: 10.1111/j.1559-1816.2000.tb02323.x]

38. Milne S, Sheeran P, Orbell S. Prediction and Intervention in Health-Related Behavior: A Meta-Analytic Review of Protection Motivation Theory. J Appl Social Pyschol 2000 Jan;30(1):106-143. [doi: 10.1111/j.1559-1816.2000.tb02308.x]

39. Jones CJ, Smith H, Llewellyn C. Evaluating the effectiveness of health belief model interventions in improving adherence: a systematic review. Health Psychol Rev 2014;8(3):253-269. [doi: 10.1080/17437199.2013.802623] [Medline: 25053213]

40. Jo SC, Han YJ. A Study on the Effect of Health Belief Factors on the Acceptance of Mobile Healthcare : Focusing on Mediating Effects of Perceived Usefulness. RIR 2020 May 30;43(2):263-280. [doi: 10.33932/rir.43.2.12]

41. Yee TS, Seong LC, Chin WS. Patient's Intention to Use Mobile Health App. Journal of Management Research 2019 May 28;11(3):18-35 [FREE Full text] [doi: 10.5296/jmr.v11i3.14776]

42. Askari M, Klaver NS, van Gestel TJ, van de Klundert J. Intention to use Medical Apps Among Older Adults in the Netherlands: Cross-Sectional Study. J Med Internet Res 2020 Sep 04;22(9):e18080 [FREE Full text] [doi: 10.2196/18080] [Medline: 32624465]

43. Bhattacherjee A. Understanding Information Systems Continuance: An Expectation-Confirmation Model. MIS Quarterly 2001 Sep;25(3):351-370 [FREE Full text] [doi: 10.2307/3250921]

44. Cho J. The impact of post-adoption beliefs on the continued use of health apps. Int J Med Inform 2016 Mar;87:75-83. [doi: 10.1016/j.ijmedinf.2015.12.016] [Medline: 26806714]

45. Devoy S, Simpson EEA. Help-seeking intentions for early dementia diagnosis in a sample of Irish adults. Aging Ment Health 2017 Aug;21(8):870-878. [doi: 10.1080/13607863.2016.1179262] [Medline: 27149181]

46. Kim S, Sargent-Cox KA, Anstey KJ. A qualitative study of older and middle-aged adults' perception and attitudes towards dementia and dementia risk reduction. J Adv Nurs 2015 Jul;71(7):1694-1703. [doi: 10.1111/jan.12641] [Medline: 25702823]

47. Park J, Shin JH. Factors Influencing the Dementia-Preventive Behaviors among Middle-Aged Persons with Chronic Diseases in Korea. Int J Environ Res Public Health 2021 Mar 13;18(6):2936 [FREE Full text] [doi: 10.3390/ijerph18062936] [Medline: 33805592]

48. Cations M, Radisic G, Crotty M, Laver KE. What does the general public understand about prevention and treatment of dementia? A systematic review of population-based surveys. PLoS One 2018 Apr 19;13(4):e0196085 [FREE Full text] [doi: 10.1371/journal.pone.0196085] [Medline: 29672559]

49. Smith BJ, Ali S, Quach H. The motivation and actions of Australians concerning brain health and dementia risk reduction. Health Promot J Austr 2015 Aug;26(2):115-121. [doi: 10.1071/HE14111] [Medline: 26210295]

50. Werner P, Goldberg S, Mandel S, Korczyn AD. Gender differences in lay persons' beliefs and knowledge about Alzheimer's disease (AD): a national representative study of Israeli adults. Arch Gerontol Geriatr 2013;56(2):400-404. [doi: 10.1016/j.archger.2012.11.001] [Medline: 23219063]

51. Kessler E, Bowen CE, Baer M, Froelich L, Wahl H. Dementia worry: a psychological examination of an unexplored phenomenon. Eur J Ageing 2012 Dec;9(4):275-284 [FREE Full text] [doi: 10.1007/s10433-012-0242-8] [Medline: 28804427]

52. Maxfield M, Greenberg J. Anticipated Stigma and Dementia-Related Anxiety in Middle-Aged and Older Adults. GeroPsych (Bern) 2021 Mar;34(1):13-22. [doi: 10.1024/1662-9647/a000234] [Medline: 34276334]

53. Lee W, Gray SL, Zaslavsky O, Barthold D, Marcum ZA. Association between having a family member with dementia and perceptions of dementia preventability. Aging Ment Health 2020 Nov 02:1-7. [doi: 10.1080/13607863.2020.1839866] [Medline: 33131283]

\section{Abbreviations}

AD: Alzheimer disease

ANOVA: analysis of variance

HBM: health belief model

OR: odds ratio 
Edited by R Kukafka; submitted 30.06.21; peer-reviewed by G Shakerinejad, R Eckhoff; comments to author 13.11.21; revised version received 22.11.21; accepted 03.12.21; published 14.01.22

Please cite as:

Lee J, Lim JM

Factors Associated With the Experience of Cognitive Training Apps for the Prevention of Dementia: Cross-sectional Study Using an Extended Health Belief Model

J Med Internet Res 2022;24(1):e31664

URL: https://www.jmir.org/2022/1/e31664

doi: $\underline{10.2196 / 31664}$

PMID:

(CJaegyeong Lee, Jung Min Lim. Originally published in the Journal of Medical Internet Research (https://www.jmir.org), 14.01.2022. This is an open-access article distributed under the terms of the Creative Commons Attribution License (https://creativecommons.org/licenses/by/4.0/), which permits unrestricted use, distribution, and reproduction in any medium, provided the original work, first published in the Journal of Medical Internet Research, is properly cited. The complete bibliographic information, a link to the original publication on https://www.jmir.org/, as well as this copyright and license information must be included. 